\title{
Pembinaan Iklim Sekolah K-7 Sebagai Upaya Meningkatkan Efektivitas Belajar: Best Practises
}

\author{
Asmara Nini \\ Dinas Pendidikan dan Kebudayaan \\ Kabupaten Pasaman Provinsi Sumatera Barat
}

\begin{abstract}
:
Seven-K School Climate Development as an Effort to Improve the Effectiveness of Learning in Pasaman District managerial schools, as well as how teachers and students attempt to utilize the climate and school culture as a source of learning. For Citizenship Education (PKn) teachers and Social Sciences (IPS) teachers. Principal's leadership, influenced by supervision, school climate, and community support. Aspects of school discipline need to be improved, as seen from the incomplete recap of the presence of teachers and staff; the absence of student records that violate the code of conduct; the absence of proof of examination of teacher and employee assignments by the principal; not all teachers make learning tools (only 50-60\%); incomplete list of teachers attending the flag ceremony; there is no government regulation (PP 30/1980) regarding the rules of civil servants; there are no programs and documents giving rewards and punishment to teachers and employees. In the field of management: incomplete description of the tasks of each organization; there is no evaluation book on the implementation of school programs, not yet transparent school financial management. In the field of Seventh-K (K7) (cleanliness, beauty, order, safety, family, shade, and health) there are still findings such as student toilet cleanliness that is poorly maintained, adequate trash bins are not yet available, school gardens are poorly maintained, many students are late at hours first, picket teachers have not been functioning to improve discipline, and school yearning has not been sufficient In terms of output or quantitative learning outcomes, it has also not shown encouraging results. The $2018 \mathrm{UN}$ results for the junior high school level, the writer's managerial area reached a graduation rate of $93.81 \%$. Although UN results can be categorized as good because the graduation rate reaches $95.78 \%$ (2017); 96.59\% (2018), but the results are almost positively correlated with high school graduation rates.
\end{abstract}

Keywords: School Climate and Culture, Quality Improvement

\section{PENDAHULUAN}

Keberhasilan suatu sekolah dalam mendidik dan membelajarkan peserta didiknya dipengaruhi oleh banyak faktor, antara lain, adalah keprofesionalan guru, kepemimpinan kepala sekolah, dukungan masyarakat, supervisi, dan iklim sekolah. Masing-masing faktor tersebut saling berinteraksi dan memberikan sumbangan terhadap pencapaian peserta didik dalam belajar. Apabila faktor-faktor tersebut berada dalam 

Best Practices. Cendekia (2019), 13(2): 133 140. DOI: 10.30957/cendekia.v13i2.601.

kondisi baik maka hasil pendidikan diperkirakan akan baik pula. Namun, faktor-faktor tersebut juga saling mempengaruhi. Kepemimpinan kepala sekolah, misalnya, dipengaruhi oleh pengawasan, iklim sekolah, dan dukungan masyarakat. Dukungan masyarakat dipengaruhi oleh kepemimpinan kepala sekolah dan keprofesionalan guru. Keprofesionalan guru dipengaruhi oleh kepemimpinan kepala sekolah, iklim sekolah dan sebagainya.

Iklim sekolah perlu mendapat perhatian lebih. Aspek iklim sekolah itu antara lain, lingkungan sekolah, fasilitas sekolah, kesempatan berpartisipasi bagi peserta didik, sistem hukuman dan hadiah, pengharapan warga sekolah, proses organisasi kolegial, kedekatan guru dan peserta didik, hubungan sesama guru, hubungan guru dengan kepala sekolah dan staf administrasi, kerjasama dan saling mendukung orang tua peserta didik dengan guru, moral dan norma kelompok, budaya kerja, dan motivasi kerja guru. Mengingat besarnya pengaruh iklim sekolah terhadap motivasi dan budaya kerja positif warga sekolah maka seluruh warga sekolah bersama-sama menciptakan iklim sekolah yang kondusif. Kepala sekolah sebagai manejer sekolah diharapkan menjadi pemimpin yang bijaksana dan menjadi suri tauladan oleh guru, peserta didik, dan warga sekolah lainnya. Para guru diharapkan mampu menjalin kekeluargaan antar sesama guru, kepala sekolah, dan karyawan dan masyarakat lingkungan sekolah. Disiplin tidak hanya menjadi kepedulian pimpinan sekolah, tetapi juga menjadi kepedulian semua warga sekolah. Pandangan masyarakat, komitmen dalam menjalankan peraturan sekolah, keindahan sekolah merupakan unsur-unsur yang perlu menjadi perhatian semua warga sekolah agar terciptanya iklim sekolah yang menyenangkan sebagai tempat belajar.

Iklim sekolah atau yang biasa juga disebut dengan budaya sekolah atau atmosfer sekolah cukup besar pengaruhnya terhadap kinerja guru. Guru yang membawa ide-ide pengembangan, misalnya, dapat saja "kesandung" apabila iklim sekolah kurang mendukung. Apabila iklim sekolah positif maka kinerja guru akan positif pula; sebaliknya, iklim sekolah yang negatif akan menghambat kinerja guru.

Aspek iklim sekolah itu antara lain, lingkungan sekolah, fasilitas sekolah, kesempatan berpartisipasi bagi peserta didik, sistem hukuman dan hadiah, pengharapan warga sekolah, proses organisasi kolegial, kedekatan guru dan peserta didik, hubungan sesama guru, hubungan guru dengan kepala sekolah dan staf administrasi, kerjasama dan saling mendukung orang tua peserta didik dengan guru, moral dan norma kelompok, budaya kerja, dan motivasi kerja guru. Mengingat besarnya pengaruh iklim sekolah terhadap motivasi dan budaya kerja positif warga sekolah maka sangatlah patut seluruh warga sekolah secara bersama-sama menciptakan iklim sekolah yang kondusif sesuai dengan peran dan fungsinya masing-masing. Kepala sekolah sebagai manejer sekolah diharapkan menjadi pemimpin yang bijaksana dan dapat dijadikan contoh oleh guru, peserta didik, dan warga sekolah lainnya. Para guru diharapkan mampu menjalin kekeluargaan yang baik antar sesama guru, kepala sekolah, dan karyawan. Begitu juga guru dan siswa, guru dan masyarakat lingkungan sekolah, dan sebagainya.

Disiplin tidak hanya menjadi kepedulian pimpinan sekolah, tetapi juga menjadi kepedulian semua warga sekolah. Pandangan masyarakat, komitmen dalam menjalankan peraturan sekolah, keindahan sekolah merupakan unsur-unsur yang perlu 
menjadi perhatian semua warga sekolah agar terciptanya iklim sekolah yang menyenangkan sebagai tempat belajar.

Dengan penciptaan iklim atau budaya sekolah seperti dijelaskan di atas, dalam diri semua warga sekolah akan tumbuh sugesti yang tinggi dalam menjalankan pekerjaan dan tugas-tugasnya. Kepala sekolah akan merasakan beban sebagai kepala sekolah menjadi lebih ringan karena adanya kerjasama yang baik dengan guru, staf administrasi.erta semua stock holder sekolah.

Terciptanya iklim sekolah yang baik tentu menjadi harapan semua warga sekolah dan masyarakat. Akan tetapi, kenyataan berdasarkan hasil survey masih ada sekolah yang belum memiliki iklim sekolah yang positif. Aspek disiplin sekolah perlu ditingkatkan karena masih terdapat temuan ketidakdisiplinan sebagai berikut, antara lain: (a) tidak lengkapnya rekap kehadiran guru dan pegawai; (b) tidak lengkap/tidak ada catatan siswa yang melanggar tata tertib; (c) tidak adanya bukti pemeriksaan tugas guru dan karyawan oleh kepala sekolah; (d) belum semua guru yang membuat perangkat pembelajaran (cuma 50-60\%); (e) tidak lengkapnya daftar hadir guru yang mengikuti upacara bendera; (f) tidak terdapat peraturan pemerintah (PP 30/tahun 1980) tentang tata tertib pegawai negeri sipil; (h) tidak ada program dan dokumen pemberian hadiah dan sanksi (reword and punishment) kepada guru dan karyawan. Dalam bidang manajemen masih terdapat temuan sebagai berikut: (a) belum lengkap uraian tugas masing-masing organisasi; (b) belum ada buku evaluasi pelaksanaan program sekolah (c) belum transparannya manajemen keuangan sekolah

Dalam bidang K7 (kebersihan, keindahan, ketertiban, keamanan, kekeluargaan, kerindangan, dan kesehatan) masih terdapat temuan seperti (a) kebersihan kamar kecil siswa kurang terpelihara, (b) belum tersedia tong sampah yang memadai, (c) kurang terawatnya taman sekolah, (d) banyak siswa terlambat pada jam pertama, (e) guru piket belum berfungsi meningkatkan disiplin, (f) dan kerindangan sekolah belum memadai

Dari segi output atau hasil belajar secara kuantitatif juga belum menunjukkan hasil yang menggembirakan. Hasil UN tahun 2018 untuk tingkat SMP, wilayah managerial penulis mencapai tingkat kelulusan 93.81\%. Meskipun hasil UN dapat dikategorikan baik karena tingkat kelulusan mencapai 95,78\% (2017); 96,59\% (2018), namun hasil itu sudah hampir berkorelasi positif dengan tingkat kelulusan masuk SMA. Dengan demikian dapat disimpulkan bahwa hasil pendidikan di wilayah binaan managerial penulis boleh dikatakan cukup memadai.

Berdasarkan kenyataan di atas, diperlukan berbagai upaya pembenahan dalam penyelenggaraan pendidikan. Salah satu yang cukup berpengaruh adalah iklim sekolah atau budaya sekolah. Iklim yang kondusif sangatlah memungkinkan terjadinya proses pembelajaran secara efektif. Kepala sekolah, guru, staf administrasi, dan siswa memerlukan kenyamanan dan ketertiban sebagai motivasi dalam melaksanakan tugas dan kewajiban masing-masing. Suasana kondusif tersebut dapat menumbuhkan semangat dalam bekerja dan belajar sehingga pembelajaran dapat berjalan secara efektif.aman dan tertib.

Masalahnya adalah bagaimanakah Dinas Pendidikan di wilayah kerja mengintensifkan guru untuk membantu terciptanya iklim sekolah dalam upaya peningkatan kinerja guru? Apakah guru telah melakukan tugas dengan baik? Apakah fasilitas sudah disediakan atau belum? Apakah kualifikasi dan kompetensi guru sudah 
memadai atau belum sesuai dengan peraturan yang berlaku dan tantangan masalah pendidikan yang dihadapi?

Di samping itu, iklim sekolah yang belum tercipta dengan baik juga berdampak pada kinerja guru. Masalah yang ada di seputar iklim sekolah adalah upaya apakah yang telah dilakukan pihak sekolah untuk mengkondusifkan iklim sekolah baik berupa regulasi atau tradisi yang dikembangkan di sekolah. Ke dalam aspek iklim sekolah termasuk budaya kerja guru, kepemimpinan kepala sekolah, motivas kerja, hubungan sosial dan emosional antar sesama guru dan antara guru dengan kepala sekolah dan staf administrasi, hubungan sekolah dengan masyarakat sekitar, dan lain-lain.

\section{Rumusan Masalah}

Berdasarkan latar belakang dan identifikasi masalah sebagaimana dikemukakan di atas maka masalah yang dibahas dalam tulisan ini adalah:

1. Apa yang dimaksud dengan iklim sekolah serta faktor yang mempengaruhinya?

2. Bagaimana cara melaksanakan pembinaan iklim sekolah melalui forum diskusi?

Tujuan Penulisan ini adalah: a. Guru, dapat menyempurnakan metode pembelajaran yang diterapkan di sekolah sehingga dapat meningkatkan pembelajaran aktif, inovatif, kreativitas,dan menyenangkan hasil belajar siswa. b. Kepala Sekolah, dapat memberikan motivasi kepada guru yang lain untuk menyempurnakan metode dan setrategi pembelajaran yang diterapkan di sekolah dalam upaya meningkatkan hasil belajar siswa. c. Pengawas Sekolah, dapat membantu dalam membimbing guru dalam pelaksanaan tugasnya sehingga dapat meningkatkan kompetensi dan profesionalisme guru.

\section{HASIL DAN PEMBAHASAN}

\subsection{Hakikat Iklim Sekolah}

Secara harfiah pengertian iklim adalah "suasana; keadaan", sedangkan sekolah adalah "lembaga untuk belajar dan mengajar serta tempat menerima dan memberi pelajaran." (Moeliono,1991:369 dan 892). Jadi, iklim sekolah adalah suasana atau keadaan yang memperlihatkan kebiasaan-kebiasaan yang berlaku di sekolah yang turut mempengaruhi budaya kerja warganya.

Konsep iklim sekolah diistilahkan secara berbeda oleh para ahli. Menurut Sackney (1988), sepanjang dua dekade terakhir telah digunakan istilah seperti atmosphere, feelings, tone, setting, millieu, culture, school ethos, dan the psychological context untuk pengertian iklim sekolah. Dalam Best practice ini digunakan istilah "iklim sekolah" untuk menjelaskan tentang suasana dan karakteristik sekolah yang berpengaruh terhadap warga sekolah dalam menjalankan aktivitasnya. Seperti juga dikatakan oleh Hadiyanto (2000), iklim sekolah sebagai suasana yang muncul karena adanya hubungan antarpersonal dalam lingkungan sekolah.

Menurut Hoy dan Miskel (1995) iklim sekolah merupakan seperangkat karakterisik internal yang membedakan satu sekolah dengan sekolah lainnya dan mempengaruhi tingkah laku orang-orang di dalamnya. Iklim di suatu sekolah merupakan hasil akhir dari interaksi siswa dan guru yang bekerja untuk keseimbangan organisasi dan individu sebagai bagian dari sistem sosial. Sergiovani (1987) berpendapat bahwa iklim sekolah lebih mengarah pada sifat dan hakikat hubungan antar 
pribadi yang diwujudkan dalam sikap dan perilaku guru, peserta didik, dan kepala sekolah. Setiap guru jelas menginginkan suasana yang menyenangkan dalam bertugas. Suasana yang kondusif itu dapat mempengaruhi warga sekolah dalam menjalankan tugasnya masing-masing. Timpe (1993) menjelaskan bahwa guru akan bekerja lebih optimal jika didukung oleh iklim sekolah yang menyenangkan karena hal tersebut dapat dijadikan sebagai motivasi untuk menghasilkan prestasi kerja yang lebih baik. Sebaliknya, iklim sekolah yang tidak kondusif menyebabkan guru tidak termotivasi melaksanakan tugas sebagaimana mestinya.

Chand (1991) juga mengemukakan bahwa iklim sekolah yang baik penting untuk (1) terciptanya suasana pembelajaran yang lebih baik; (2) membangkitkan semangat kerja; (3) meningkatkan sumbangan kepercayaan masyarakat terhadap keberadaan sekolah sebagai wadah pengembangan potensi. Semua itu berkaitan dengan pelaksanaan tugas masing-masing komponen yang ada di sekolah.

Berdasarkan uraian di atas dapat disimpulkan bahwa iklim sekolah yang baik sangat penting bagi guru dalam melaksanakan tugasnya karena akan ikut menentukan hasil kerja guru tersebut. Untuk itu iklim sekolah harus selalu dipelihara agar tetap kondusif dan menyenangkan.

\subsection{Faktor-Faktor yang Mempengaruhi Iklim Sekolah}

Iklim sekolah dipengaruhi oleh beberapa faktor. Menurut Pidarta (1995) ada lima faktor yang mempengaruhi iklim sekolah yaitu: 1. Penempatan personalia, yaitu yang berhubungan dengan penempatan tugas dan penempatan guru sebagai pegawai. 2 . Pembinaan komunikasi, berhubungan dengan kegiatan membina komunikasi yang efektif antar warga sekolah. 3. Dinamisasi dan penyelesaian konflik, berhubungan dengan perkembangan sekolah dan bagaimana menyelesaikan masalah yang ada. 4. Pemanfaatan informasi, berhubungan dengan bagaimana menyikapi dan menggunakan informasi yang ada. 5. Peningkatan lingkungan kerja yaitu berhubungan dengan menciptakan lingkungan yang dapat membantu proses pencapaian tujuan.

Hoy dan Miskel (1995) juga mengemukakan beberapa faktor yang mempengaruhi iklim sekolah antara lain: 1. Rintangan, berhubungan dengan perasaan guru-guru dengan tugas-tugas rutin, pekerjaan kepanitiaan, dan lainnya yang dianggap guru sebagai pekerjaan yang kurang menyenangkan. 2. Keintiman, hubungan antarpribadi guru yang erat dan menyenangkan. 3. Keterbatasan, adanya kecenderungan guru melakukan tugas-tugas secara asal-asalan dan tidak bertanggung jawab dalam melaksanakannya. 4. Semangat, yaitu kemauan mengupayakan kepuasan sosial dan kepuasan pada hasil. 5. Kejauhan, berhubungan dengan perilaku kepala sekolah yang tidak akrab, terlalu formal, dan menjaga jarak dengan guru. 6. Dorongan, berhubungan dengan perilaku kepala sekolah yang dinamis dalam menggerakkan sekolah dengan memberikan keteladanan yang patut dicontoh. 7. Pertimbangan, berhubungan dengan perilaku hangat dan akrab.

Menurut Steers (1987), salah satu faktor yang mempengaruhi iklim sekolah adalah keterbukaan. Keterbukaan diartikan sebagai sikap saling bertoleransi, memberi dan menerima masukan dari orang lain. Sikap terbuka sangatlah diperlukan agar tercipta suasana yang menyenangkan. Dengan keterbukaan komunikasi guru dengan semua 
warga sekolah akan lancar dan efektif sehingga dapat membantu menciptakan iklim sekolah yang kondusif.

Jadi, iklim sekolah sangat dipengaruhi oleh suasana internal sekolah yang tercipta terutama melalui pola hubungan antar pribadi personal sekolah. Terciptanya iklim sekolah yang positif dan kondusif akan memberikan pengaruh yang baik dalam proses belajar mengajar di sekolah.

\subsection{Pembinaan Iklim Sekolah}

Tugas pokok guru di sekolah adalah melakukan pembelajaran terhadap penyelenggaraan pendidikan di sekolah dengan segala komponen yang mempengaruhinya. Di samping komponen pembelajaran, komponen-komponen manajemen yang berpengaruh terhadap mutu pelaksanaan pendidikan haruslah dilaksanakan secara kontinyu dan terprogram. Hasil proses pembelajaran inilah yang diharapkan mampu meningkatkan mutu pembelajaran menjadi lebih baik.

Pada dasarnya komponen yang terkait dengan iklim sekolah cukup luas sekali. Tumbuhnya iklim sekolah yang kondusif di sekolah dapat dilaksanakan dengan mengintensifkan kinerja guru, kepala sekolah dalam bidang disiplin sekolah dan program K7. Dalam pelaksanaannya dapat memulai kegiatan proses pembelajaran dengan mengamati disiplin atau efektivitas pembelajaran di sekolah. Data ini dapat diperoleh jika guru sudah berada di sekolah sebelum jam masuk sekolah. Disiplin sekolah pada jam pertama belajar merupakan fenomena kondisi sesungguhnya dari suatu sekolah.

\subsection{Supervisi K7}

Supervisi K7 (kedisiplinan, kebersihan, ketertiban, keindahan, kerindangan, kesehatan, dan keamanan) juga amat berperan terhadap terciptanya iklim sekolah yang baik. Setiap unsur K7 di atas dapat diciptakan melalui kolaborasi antara guru, kepala sekolah, dan semua warga sekolah. Guru mestilah memiliki komitmen dan dedikasi yang memadai sebagai guru atau warga sekolah. Kepala sekolah juga harus menunjukkan kinerjanya secara baik. Kepala sekolah bertanggung jawab melakukan pembinaan secara efektif. Dengan pola inilah kolaborasi dapat dilakukan sehingga diharapkan terciptalah iklim sekolah yang menimbulkan efektivitas pembelajaran.

\subsection{Pembinaan Iklim Sekolah Berbasis Masalah Melalui Forum Diskusi}

Data-data lapangan tentang iklim sekolah merupakan data yang perlu dijadikan bahan untuk pembinaan. Berdasarkan data-data yang dihimpun melalui pengamatan dan wawancara, guru dapat memahami dan mengidentifikasi masalah-masalah iklim sekolah yang diduga menjadi kendala terhadap terciptanya efektivitas pembelajaran. Adanya masalah, sedikit atau banyak jelas menjadi kendala tercapainya tujuan pendidikan. Untuk mengatasinya tentu perlu upaya tertentu yang akan dilakukan oleh kepala sekolah, guru, dan semua warga sekolah lainnya, serta pengawas sekolah yang secara kedinasan turut bertanggung jawab terhadap mutu pendidikan.

Sebagai kepala sekolah yang berperan memberikan penilaian dan pembinaan di sekolah masalah-masalah yang sudah teridentifikasi perlu dicari solusinya secara bersama-sama. Pemecahan masalah perlu dipikirkan agar iklim sekolah dapat tercipta 
seperti yang diharapkan oleh seluruh warga sekolah. Seperti yang disampaikan Sanjaya dalam Sudjana (2000:139) bahwa pemecahan masalah hendaknya memenuhi dua kepentingan: (1) pemecahan masalah harus mengarah pada tercapainya suatu situasi yang diinginkan, (2) seseorang yang melakukan kegiatan pemecahan masalah hendaknya mampu bertindak untuk keluar dari situasi sekarang dan kemudian masuk ke situasi yang diinginkan.

Untuk memecahkan masalah iklim sekolah tersebut, guru bersama kepala sekolah dapat mengawali pembinaan dengan melakukan kegiatan dalam suatu forum diskusi dengan semua warga sekolah. Melalui diskusi ini semua warga sekolah diminta untuk mengemukakan ide, perasaan, dan komentarnya dalam upaya menemukan jalan keluar yang tepat dari permasalahan yang ada. Dengan cara ini penyelesaian masalah dapat diatasi secara transparan sesuai dengan aturan-aturan yang berlaku, kesepakatan berbagai pihak tanpa diwarnai sikap emosi dari warga sekolah.

\section{SIMPULAN}

Pembinaan iklim sekolah berbasis masalah membutuhkan kecakapan dan kiat tersendiri dalam mewujudkannya karena tidak sedikit kepala sekolah yang 'alergi' jika permasalahan-permasalahan sekolah dihadapkan kepada forum guru. Akan tetapi, demi terselenggaranya efektifitas pembelajaran di sekolah pembinaan iklim sekolah amatlah perlu dilakukan. Semua warga sekolah, siswa, guru, staf administrasi, pesuruh atau penjaga sekolah sangatlah membutuhkan suasana yang menyenangkan dan memungkinkan mereka bekerja dengan hati yang aman dan nyaman, termotivasi untuk berdedikasi bukan sekadar menjalankan tugas semata.

\section{SARAN}

Pentingnya iklim sekolah ada beberapa alternatif pembinaan yang bisa dilakukan guru bahwa iklim sekolah yang kondusif mestilah menjadi perhatian semua warga sekolah. kepala sekolah dan guru secara kolaborasi harus berusaha untuk menciptakan iklim sekolah yang kondusif. Di antara bentuk pembinaan yang bisa dilakukan adalah mengintensifkan supervise, disiplin sekolah, K7 dilombakan antar kelas minimal setiap bulannya, dan pembinaan berbasis masalah melalui gelar forum diskusi bersama seluruh warga sekolah. Guru mampu membuat skenario pembelajaran dengan memanfaakan iklim sekolah sebagai sumber belajar dan melaksanakan pembelajaran dengan memanfaakan iklim dan budaya sekolah yang konduif serta mampu memanfaatkan diskusi kelompok kerja guru secara efektif dan efesien dalam memecahkan masalah yang terkait dengan kegiatan pembelajaran. Cara-cara ini diharapkan mampu mengatasi masalah kurang efektifnya pembelajaran dan rendahnya kinerja guru karena kurang kondusifnya iklim sekolah.

\section{DAFTAR PUSTAKA}

Depdiknas. 2006. Undang-Undang Republik Indonesia Nomor 14 Tahun 2005 tentang Guru dan Dosen. Jakarta: Depdiknas.

Hadiyanto. 2000. Iklim Sekolah, Iklim Kelas. Teori, Riset, dan Aplikasi. Padang: UNP. Moeliono, Anton M (Penyunting Penyelia).1991. Kamus Besar Bahasa Indonesia Edisi Kedua.Jakarta: Balai Pustaka. 
CENDEKIA, Vol. 13 No. 2 Oktober 2019

p ISSN: 1978 2098; e ISSN: 2407 8557

Https://soloclcs.org; Email: cendekiaoslo@gmail.com

Center of Language and Cultural Studies, Surakarta, Indonesia

Nini, Asmara. (2019). Pembinaan Iklim Sekolah K 7 sebagai Upaya Meningkatkan Efektivitas Belajar: Best Practices. Cendekia (2019), 13(2): 133 140. DOI: 10.30957/cendekia.v13i2.601.

Sergiovani, T.J. 1997. The Principalship a Reflektive, Practice-Perspektives Massachuset. Allyn an bacon. 